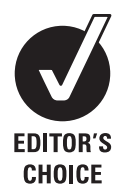

- Additional material and tables are published online only. To view these files please visit the journal online (http://jmg.bmj.com).

${ }^{1}$ Medical Genetics, Department of Reproductive Sciences, Development and Public Health, IRCCS-Burlo Garofolo Children Hospital, Unversity of Trieste, Trieste, Italy

${ }^{2}$ Institute of Genetics and Biophysics "A.Buzzati-Traverso", CNR, Naples, Italy

${ }^{3}$ Institute of Population Genetics, National Research Council of Italy, Sassari, Italy ${ }^{4}$ Shardna life science, Pula, Cagliari, Italy

${ }^{5}$ Centre for Population Health Sciences, The University of Edinburgh Medical School, Edinburgh, UK

${ }^{6} \mathrm{MRC}$ Human Gentics Unit, Institute of Genetics and Molecular Medicine, Western General Hospital, Edinburgh, UK ${ }^{7}$ Croatian Centre for Global Health, University of Split Medical School, Split, Croatia

\section{Correspondence to}

Paolo Gasparini, Medical Genetics, Department of Reproductive Sciences and Development, IRCCS-Burlo Garofolo, University of Trieste, Via dell'Istria 65, Trieste 34100, Italy; gasparini@burlo.trieste.it

GG and NP contributed equally.

Received 17 December 2010 Revised 8 February 2011 Accepted 3 March 2011 Published Online First 14 April 2011

\title{
Hearing function and thresholds: a genome-wide association study in European isolated populations identifies new loci and pathways
}

\author{
Giorgia Girotto, ${ }^{1}$ Nicola Pirastu, ${ }^{1}$ Rossella Sorice, ${ }^{2}$ Ginevra Biino, ${ }^{3,4}$ Harry Campbell, ${ }^{5}$ \\ Adamo P d'Adamo, ${ }^{1}$ Nicholas D Hastie, ${ }^{6}$ Teresa Nutile, ${ }^{2}$ Ozren Polasek, ${ }^{5,7}$ \\ Laura Portas, ${ }^{3}$ Igor Rudan, ${ }^{5,7}$ Sheila Ulivi, ${ }^{1}$ Tatijana Zemunik, ${ }^{7}$ Alan F Wright, ${ }^{6}$ \\ Marina Ciullo, ${ }^{2}$ Caroline Hayward, ${ }^{6}$ Mario Pirastu, ${ }^{3,4}$ Paolo Gasparini ${ }^{1}$
}

\section{ABSTRACT}

Background Hearing is a complex trait, but until now only a few genes are known to contribute to variability of this process. In order to discover genes and pathways that underlie auditory function, a genome-wide association study was carried out within the International Consortium G-EAR.

Methods Meta-analysis of genome-wide association study's data from six isolated populations of European ancestry for an overall number of 3417 individuals.

Results Eight suggestive significant loci $\left(p<10^{-7}\right)$ were detected with a series of genes expressed within the inner ear such as: DCLK1, PTPRD, GRM8, CMIP. Additional biological candidates marked by a single nucleotide polymorphism (SNP) with a suggestive association $\left(p<10^{-6}\right)$ were identified, as well as loci encompassing 'gene desert regions' - genes of unknown function or genes whose function has not be linked to hearing so far. Some of these new loci map to already known hereditary hearing loss loci whose genes still need to be identified. Data have also been used to construct a highly significant 'in silico' pathway for hearing function characterised by a network of 49 genes, 34 of which are certainly expressed in the ear.

Conclusion These results provide new insights into the molecular basis of hearing function and may suggest new targets for hearing impairment treatment and prevention.

\section{INTRODUCTION}

The hearing system is characterised by three structures-(1) the outer part, (2) the middle ear, and (3) the inner ear-and they all play a role in hearing function. The hearing system is difficult to study through biochemical routes, due to the small amounts of tissue available for analysis and by key molecules that may be present in only a few tens of copies per cell, thus compounding the difficulty. ${ }^{1}$ Hair cells of the inner ear are constituted by stereocilia arranged in bundles at their upper surface, packed with actin filaments, and deflected by the vibrations of sound. ${ }^{1}$ This activity opens ion channels modulating potential within the cell. Cell activation releases neurotransmitters to synaptic junctions between hair cells and neural fibres of the auditory nerve. The neural spike subsequently propagates in the auditory nerve fibre. Nerve impulses are finally perceived by the brain, primarily in the temporal lobe, where they can be processed and assigned meaning.

Little is known about the molecular basis of variation of normal hearing function. Several molecules have been identified as having a role in auditory function and hair cell transduction because they are specifically expressed in or around the stereocilia, and mutations in their genes lead to hearing impairments in either humans or mice models. ${ }^{2}$ These dysfunctional proteins are involved in impaired molecular-physiologic processes of potassium and calcium homeostasis, apoptotic signalling, stereocilia linkage, mechano-electric transduction, electromotility, and many other processes. ${ }^{3}$ Briefly, these molecules include myosins which represent one of the largest groups of deafness associated molecules, adhesion protein such as cadherins, members of the ferlin family, components of the tectorial membrane, genes involved in ion homeostasis such as connexins, ${ }^{4}$ and many others. ${ }^{5}$ According to the Hereditary Hearing Loss (HHL) homepage (http:// hereditaryhearingloss.org), more than 140 loci for non-syndromic HHL have been mapped, and approximately 80 genes identified in humans. In animal models $~ 70$ loci for non-syndromic HHL and $\sim 60$ genes have been so far described.

Hearing loss can also be multifactorial or complex in causality, such as age related hearing impairment (ARHI) ${ }^{6}$ and noise induced hearing loss (NIHL), ${ }^{7}$ reflecting the interaction of a number of genetic and environmental factors. Despite some relevant efforts undertaken to identify the molecular bases of these conditions, until now only a few genes have been associated with both $\mathrm{ARHI}^{6}$ and NIHL. ${ }^{7}$ Almost all genes so far identified in all forms of hearing loss are those directly related to hearing as qualitative traits (ie, disease genes mainly involved in monogenic inherited forms), while almost nothing is known about genes implicated in defining hearing as quantitative trait (ie, thresholds) in normal hearing.

The use of isolated populations to reduce heterogeneity of complex and/or quantitative traits has already proven very useful in identifying DNA polymorphisms associated with these traits. Nevertheless, the argument about the advantage of using such populations is still an open issue. 
In principle, the inbreeding-typical of small communities-reduces genetic heterogeneity, increases homozygosity, and reduces environmental factors, providing greater power for detection of susceptibility genes. ${ }^{8} 10$ Moreover, such populations could be extremely useful to detect rare variants.

Here, we combine the power of studying isolated populations with (1) a general screening of hearing function, (2) highthroughput single nucleotide polymorphism (SNP) analysis, (3) genome-wide association studies (GWAS), and (4) up-to-date in silico pathway construction, to analyse hearing as a continuous trait and detect underlying genes and networks. To reach this goal, we analysed different hearing thresholds as well as pure tone averages (PTA) and principal components from a principal component (PC) analysis of hearing traits by performing a large meta-analysis on isolated populations coming from different European regions. Results have then been used to construct a highly significant biological pathway.

\section{SUBJECTS AND METHODS Subjects}

Within the international consortium called G-EAR, we recruited 3417 subjects from several isolated villages: Carlantino located in South Eastern Italy $(267)^{11}$; Friuli Venezia Giulia Genetic Park, ${ }^{12}$ characterised by six villages located in North Eastern Italy (968); Korcula, ${ }^{13}$ an island in the Adriatic sea (Croatia) (795); Campora and Cardile, two isolated villages located in the Cilento National's park, characterised by two different isolated villages in south western Italy (421) ${ }^{11}$; Talana (469), an isolated village from Ogliastra Genetic Park in the central part of Sardinia, Italy $^{14}$; and Split (497), an outbred not isolated population located on the Dalmatian coast (Croatia). All tests were performed using standard audiometers. Subjects underwent pure-tone audiometry, tympanogram, and acoustic reflex testing in both ears. Measurements were all obtained after any acoustically obstructing wax had been removed. The analysis of hearing function was done calculating the pure tone average of air conduction (PTA at the lower $(0.25,0.5$, and $1 \mathrm{kHz})$, medium $(0.5,1$, and $2 \mathrm{kHz})$, and high frequencies $(4,8 \mathrm{kHz}))$.

A questionnaire to obtain sociodemographic information, as well as data on physical activity (ie, job, sport, etc), lifestyle (eg, smoking, alcohol consumption, coffee intake, diet including taste and food preferences, etc), clinical examinations (psychological, neurological, cardiological, etc), clinical chemistry including blood count and more than 20 parameters, drugs, diseases and other information regarding the health status (body mass index, bone density, blood pressure, etc) have been collected for each subject. Only subjects aged 18 or older were included in the analysis. Clear familial forms of severe hearing loss have been excluded from the study.

\section{Phenotypes}

For the analyses we used only the threshold from the best ear, defined as the ear with the lowest value of hearing loss for each individual. Since age explains a large part of the hearing variance, each trait was first linearly regressed against age. Residuals from this regression were cleaned from outliers (mean $\pm 6 \mathrm{SD}$ ) and, since their distributions were skewed, normalised using rank normal transformation and used for the association analysis using sex as a covariate. The following quantitative traits have been tested:

- PTA at low, medium and high frequencies (PTAL, PTAM, PTAH)

- Seven different thresholds $(250 \mathrm{~Hz}, 500 \mathrm{~Hz}, 1 \mathrm{KHz}, 2 \mathrm{KHz}$, $4 \mathrm{KHz}$, and $8 \mathrm{KHz}$ )
- The first three components from PCs (PC1, PC2, PC3) estimated on all of the frequencies as previously described. ${ }^{15}$ We did not regress out sex or age before running PCA analysis and we checked that none of the components used reflected either one. Each component describes a different pattern in the data ${ }^{15}$ : PC1 is a 'size variable' that represents an overall measure of a subject's hearing ability, PC2 and PC3 are instead 'shape variables'. In particular, PC2 shows the ratio of hearing between the high and the low frequencies and is a measure of the slope of the audiogram, and PC3 contrasts the middle frequencies with the lower and higher frequencies and can be considered a measure of the concavity of an audiogram.

\section{DNA sampling and genotyping}

All studies had appropriate ethical consent and consent forms for clinical and genetic studies have been signed by each participant in the study. Blood samples were collected and used to extract DNA using standard protocols. After measuring quantity and quality of DNA, samples were genotyped with Illumina $370 \mathrm{k}$ platform (Carlantino, FVG Genetic Park, Cilento, Korcula and Split) or Affymetrix $500 \mathrm{~K}$ (Talana). Genotype quality control and data cleaning were conducted independently by each study group and are summarised in supplementary table 2. Genotypes were then imputed to the $2.5 \mathrm{M}$ HapMap CEU SNP set v22 (summary of imputation can be found in supplementary material). The same map was also used to look at regions of linkage disequilibrium (LD).

\section{Statistical analysis}

Association analysis was carried out through a mixed model linear regression where the variance/covariance matrix is the genomic kinship. The analysis was implemented in $\mathrm{GenABEL}^{16}$ package for genotyped SNPs and ProbABEL ${ }^{17}$ for imputed data. Meta-analysis was conducted using the inverse variance model as implemented in the MetABEL ${ }^{16} \mathrm{R}$ library. For PCs traits fixed effects meta-analysis was conducted where Z-scores were estimated from $p$ values and weighted on the sample size as implemented in METAL. SNPs with imputation quality (Rsq in $\mathrm{MACH})<0.3$ or with $<30$ copies of an allele in each population, were excluded. $p$ Values were estimated using the Wald test. After quality control, 3417 subjects and approximately 2.2 million SNPs were used for meta-analysis.

\section{Pathway analysis}

From each GWAs result all SNPs with $p$ values $<1 \times 10^{-4}$ have been selected. After removing duplicate loci, tagged by different SNPs, and keeping only the most significant ones, all genes that could be in LD with these SNPs based on the HapMap CEU population have been taken into account, generating a list of 1276 genes. Identification of molecular network interactions and pathway analysis of most significant GWAS loci was completed using the Ingenuity Pathway Analysis (IPA) ${ }^{18}$ tools from Ingenuity Systems (Redwood City, California, USA; http://www. ingenuity.com). Briefly, the top 48 genes (cut-off of $5 \times 10^{-5}$ ) arising from GWAS data were functionally characterised using IPA. Networks with a maximum of 70 genes or proteins were constructed, and scores were computed based on the likelihood of the genes being connected together due to random chance. A score of 2 indicates that there is a 1/100 chance that these genes are connected in a network due to random chance. Therefore, any networks with a score of 2 or above are considered statistically significant (with $>99 \%$ confidence). IPA then map these genes to a global molecular network developed from information 
contained in the Ingenuity knowledge base (a manually curated database of experimentally proven molecular interactions from published literature). IPA determines the most significantly enriched biological functions and/or related diseases by calculating the $p$ value using Fisher's exact test. Using similar methods, significantly represented canonical pathways in a set of focus genes were also determined using IPA. To run the analysis only direct interactions were taken into account. After the definition of the most significant pathways, expression data within the ear were obtained by searching the following databases: National Center for Biotechnology Information (NCBI) Gene for human and mouse, Eurexpress and Jackson Laboratory for mouse.

\section{RESULTS}

The meta-analysis succeeded in identifying some genome-wide suggestive loci associated with hearing traits, plus several additional ones strongly suggestive. All these trait-locus associations represent novel findings.

For all quantitative traits the top SNPs resulting from this analysis are listed in supplemental tables 1 (PTA), 2 (PCs), 3, and 4 (thresholds). Eight loci were strongly associated with the analysed traits $\left(\max p=2.1 \times 10^{-7}\right.$ ), while many others were in a group showing a maximum $p$ value of $1 \times 10^{-6}$. Supplemental table 1 reports the most suggestive significant GWAS data obtained on PTA. For PTAL the strongest association signal was given by rs $248626\left(p=3.1 \times 10^{-6}\right)$ located on chromosome 5 , in a region containing DIAPH1 and a cluster of protochaderin genes. ${ }^{19} 20$ Suggestive significant association with this locus has been also obtained at $500 \mathrm{~Hz}$ threshold. Another interesting SNP is rs4603971 (chromosome 3) that is in LD with KCNMB2, a potassium large conductance calcium activated channel ${ }^{21}$ It is known that several potassium channels are essential for hearing pathways. ${ }^{4}$ Moreover, KCNMB2 interacts with KCNMA1 that plays a key role in controlling the tuning of hair cells in the cochlea, regulation of transmitter release, and innate immunity. ${ }^{22}$

For PTAM, rs898967 (chromosome 16) is located within CMIP gene, which is expressed in the ear (see NCBI). Suggestive significant associations with this gene have also been found at $250 \mathrm{~Hz}, 1 \mathrm{KHz}$, and at $2 \mathrm{KHz}$. Another positive SNP is rs641113 located on chromosome 10 and is in LD with OPTN, an important gene required for myosin VI localisation at the Golgi complex. ${ }^{23}$ Myosin VI is essential for auditory and vestibular function in mammals and genetic mutations lead to hearing impairment and vestibular dysfunction in both humans and mice. $^{23}$ Finally, for PTAH, there are two interesting SNPs: rs6673959 (chromosome 1) that is in LD with the DFFB gene, a pro-apoptotic related gene expressed in the cochlear cells ${ }^{24}$; and rs10936160 located in the MFSD1 gene whose expression in the ear is already known. ${ }^{25}$ The full list of SNPs with a $p$ value $<1 \times 10^{-6}$ for the three PTAs is presented in supplemental table 1 .

Concerning PCs, a significant association was detected at PC1 (rs2687481, $\mathrm{p}=3.2 \times 10^{-7}$ ) with GRM8 gene, a glutamate receptor that inhibits adenylyl cyclase, decreasing the formation of cAMP. $^{26}$ Additional associations were detected with several SNPs located within the FGF14 gene, a member of the fibroblast growth factors family and rs7182802 $\left(p=9.9 \times 10^{-6}\right)$ located inside GABRG3, a ion channel gene differentially expressed in the ageing ear. ${ }^{27} 28$

Concerning PC2, rs6669265 ( $\left.\mathrm{p}=6 \times 10^{-7}\right)$, an SNP in LD with the NROB2 gene-whose protein is an unusual orphan receptor that contains a putative ligand binding site- has been identified. ${ }^{29}$
The protein encoded by NROB2 has been shown to interact with retinoid and thyroid hormone receptors, inhibiting their ligand dependent transcriptional activation. ${ }^{30}$ Two additional loci at $p<10^{-7}$ have been detected: one on chromosome 11 and the other one on chromosome 17.

Additional interesting SNPs are in LD with OTX2 $\left(p=5 \times 10^{-6}\right)$ that acts as a transcription factor and may play a role in brain and sensory organ development. ${ }^{18}$ Another relevant SNP is rs3783041 on chromosome $13\left(\mathrm{p}=5 \times 10^{-6}\right)$ that is in LD with DIAPH3. This gene belongs to the diaphanous family and promotes actin polymerisation. It is required for cytokinesis, stress fibre formation, and transcriptional activation of the serum response factor. ${ }^{19}$

Finally, regarding the different thresholds (supplemental table 3), rs10815873, an SNP within the PTPRD gene, was found to be strongly associated at $125 \mathrm{~Hz}$ threshold. Data available from the literature show that some members of this gene family play an important role in the hearing system. ${ }^{31}$ The SNP rs248626, already detected for PTAL (see PTA results section and supplemental table 1), was also found associated with $500 \mathrm{~Hz}$. As already mentioned, it is in $\mathrm{LD}$ with a cluster of protochaderins genes. Similarly, rs898967 located within CMIP gene (see PTA results and supplemental table 1) was found to be significantly associated with $1 \mathrm{KHz}$. Another interesting SNP at the $250 \mathrm{~Hz}$ is rs 1849287 on chromosome 15 located in the NMB gene; a member of this family (NMB1) blocks mechanotransducing ion channels in cochlear hair cells. ${ }^{32}$

Others very interesting data have been obtained at $4 \mathrm{KHz}$. The SNP rs9574464 (chromosome 13) shows an association $\left(p=3.2 \times 10^{-7}\right)$. This SNP is in LD with DCLK1 (see NCBI), a member of the protein kinase superfamily and the doublecortin family which is expressed in the inner ear. Additional suggestive SNPs are: (1) rs2660178, located on chromosome 10, which is in LD with PCDH15, a gene already involved in causing hearing loss ${ }^{5}$; (2) rs1719101, in LD with GRM8, a glutamate receptor already detected at PC1; and (3) rs16939415 in LD with $P X M P 3$, a gene related with GATA3 transcription factor, an early regulator of auditory system development. ${ }^{33}$ At $8 \mathrm{KHz}$ we identified rs9899183, on chromosome 17, that is in LD with TNFS; some members of the TNF family are important players in the initiation of acute cochlear apoptosis. ${ }^{24}$

Some of the genes/loci described here map to already known HLL loci such as DFNA30, DFNA37, DFNA42, and DFNA54 for dominant forms and DFNB17, DFNB48, DFNA57, and DFNB60 for recessive forms (see HHL), whose genes are not yet characterised.

The pathway analysis was carried out using Ingenuity software and 48 seed molecules arising from GWAS data. The analysis was able to generate only one significant pathway (figure 1 ) characterised by a very high $p$ value $\left(p=1 \times 10^{-79}\right)$ and 49 different molecules. This score reflects the extremely low probability that genes were represented in this particular network by chance alone. Thirty of them are present within the output of our GWAS, further strengthening the impact of this work, while the remaining 19 (added by the software) are other proteins that interact with them at different levels to create this predicted pathway. We then searched for different human and mouse expression databases demonstrating that 34 genes (69\%) contained within this pathway are expressed in the ear (in colour in figure 1). These findings suggest that most of the genes identified here might have an interesting role in studying normal variation of hearing function. Finally, this hypothetical pathway is also characterised by a series of IPA canonical pathways - that is, standardised pathways very well known in the literature as 


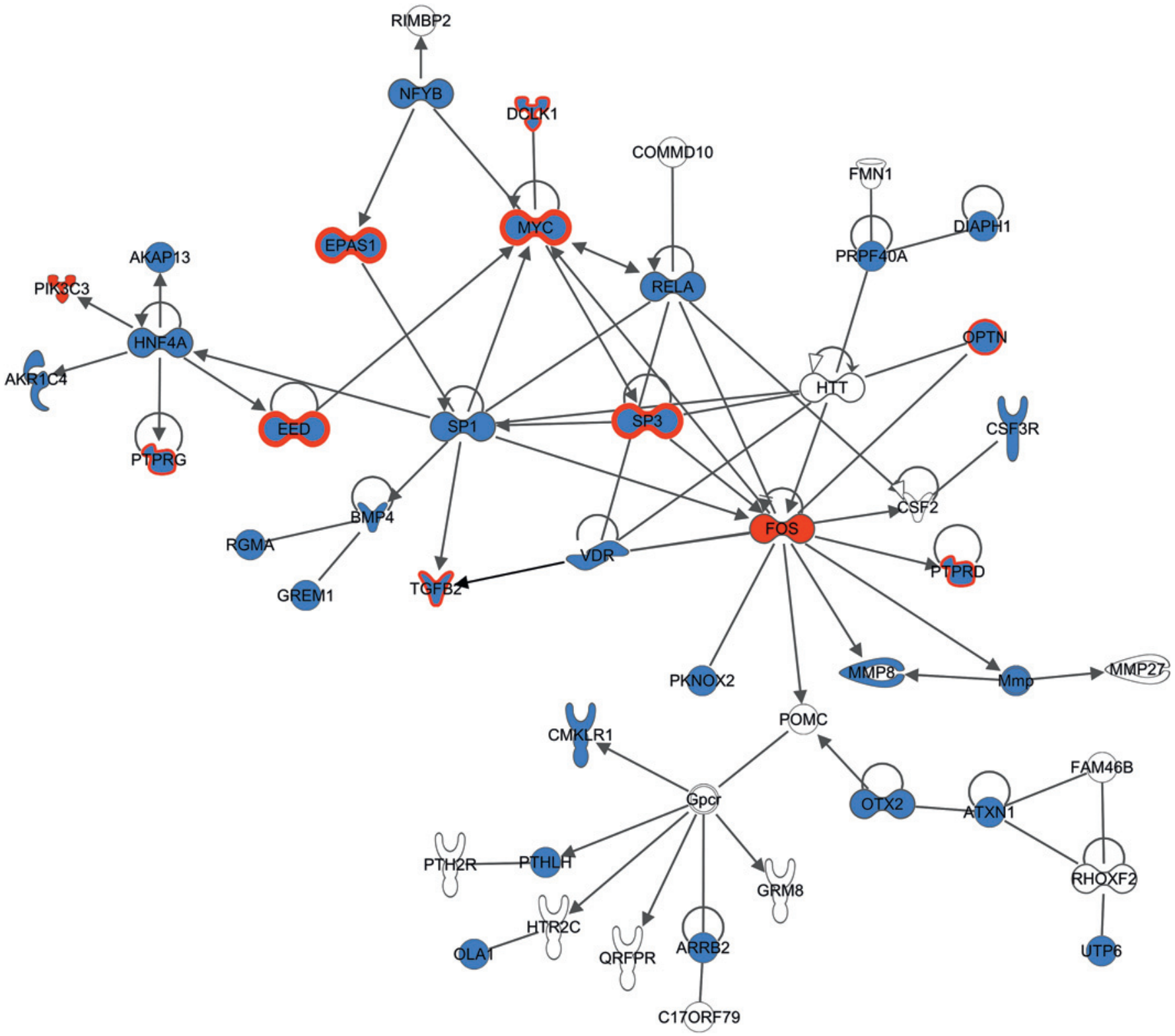

Figure 1 Ingenuity functional pathway. Ingenuity functional pathway with a score of $1 \times 10^{-79}$ represents 49 selected genes directly interacting each other. Genes coloured in red are expressed in humans, those in blue are expressed in mouse, while those with both colours are expressed in both human and mouse.

having a molecular role in a biological system. The most represented in terms of members are 'colorectal cancer metastasis signalling', 'glucocorticoid receptor signalling', and 'G-protein coupled receptor'.

\section{DISCUSSION}

GWAS became the tool of choice for the identification of genes for complex and quantitative traits, since they are able to analyse large amounts of data. ${ }^{34}$ Despite recent progress, almost nothing is known about hearing thresholds and the molecular bases of variation of normal hearing, apart from genes identified as being directly involved in HHL. Here, we present the first GWAS performed on hearing traits.

Our scan resulted in the identification of genes that have a realistic biological role in hearing function and that might be considered as good candidates for further research activities. Among them is DCLK1 $(4 \mathrm{KHz})$, doublecortin-like kinase 1, a member of the protein kinase superfamily and the doublecortin family which is expressed in the inner ear. The encoded protein is involved in several different cellular processes, including neuronal migration in the developing brain and in maturation of the nervous system. A possible role of DLCK1 in the maturation of the nervous system could be interesting for hypothesising an important role of this gene in the development of sensitive neurons that we know essential for hearing function. Another interesting gene is PTPRD $(125 \mathrm{~Hz})$, a member of the protein tyrosine phosphatase (PTP) family. PTPS are known to be signalling molecules that regulate a variety of cellular processes including cell growth, differentiation, mitotic cycle, and oncogenic transformation. Some members of this family play an important role in the hearing system. For example, studies of homologous genes in others species suggest the role of the PTPS family in promoting neurite growth and regulating neurons axon guidance-both mechanisms important for 
neuronal development. A third gene is GRM8 (PC1), a member-together with GRM7-of the group III of metabotropic glutamate receptor family which has been divided into three groups on the basis of sequence homology, putative signal transduction mechanisms, and pharmacologic properties. ${ }^{26} 34$ GRM8 and GRM7 proteins show $87 \%$ of homology and $76 \%$ of identity using BLAST analysis. Very interestingly, both associations with GRM8 and GRM7 have been detected at PC1 in two independent studies, one case-control study focused on $\mathrm{ARHI}^{6}$ (qualitative trait), and the present one on genetic bases of variation of normal hearing function (quantitative trait). A fourth significant candidate is NROB2 (PC2), whose product interacts with retinoid and thyroid hormone receptors, inhibiting their ligand dependent transcriptional activation. ${ }^{29}$ Nuclear receptors for thyroid hormone and retinoic acid are expressed in the developing sensory epithelia of the inner ear and their ligands play roles in hair cell development. ${ }^{30}$ The last candidate is CMIP at $1 \mathrm{kHz}$ ( $c-M A F$ inducing protein), a gene also expressed in the inner ear.

Additional strong biological candidates arose from results of SNPs within a group showing a maximum $\mathrm{p}$ value of $1 \times 10^{-6}$. In particular, we should mention FGF14 (PC1). ${ }^{27}$ It has been demonstrated that fibroblast growth factors have been implicated in a wide range of cellular processes. Although the role of FGF signalling in the maintenance of normal auditory function remains to be elucidated, some members of this family play a dosage sensitive role in the differentiation of the auditory sensory epithelium and have a fundamental function in cochlea development. Moreover, the inhibition of FGFs signalling could cause a reduction in hair cells, support cells and an alteration of FGFRS, which signals are produced by auditory neurons, could modify the right development of the cochlea. ${ }^{27}$ Another candidate is LPRP4 (PC3) and a quite long list of other genes such as PCHD15, KCNMB2, PIBF1, OPTN, DFFB, MFSD1, NMB, $P X M P 3$, and TNFSF12 gene. They are good candidates for variation of normal hearing function, and could be eventually considered as candidates for both NIHL and ARHI.

Since previous studies on the molecular basis of inherited hearing loss have detected loci/genes which show, as expected, a minimum overlap with those reported here, present data describe additional genes which might be involved in hearing function.

These results led to 'in silico' building of an extremely interesting pathway characterised by a network of genes in which the vast majority of them are expressed in the inner ear. Despite representing a hypothetical network, it is characterised by a series of significant functional relationships among proteins and molecules with three main canonical networks: colorectal cancer metastasis signalling; glucocorticoid receptor signalling; and G-protein coupled receptor.

As regards to the first network, it has been found recently that DFNA5 (a gene causing a non-syndromic autosomal dominant type of hearing loss) is also involved in some type of cancer such as colorectal cancer. ${ }^{35}$ Concerning the second network, although the exact mechanisms of glucocorticoid action on the inner ear are not known, the inner ear of both humans and experimental animals demonstrates an abundance of glucocorticoid receptors in both neuronal and non-neuronal tissues. Moreover, glucocorticoids are widely used to treat different hearing disorders. ${ }^{36}$ Finally, regarding the last network, some members of the G-protein coupled receptor family are known to play a relevant role in hearing function.

Moreover, among the molecules added by the Ingenuity software to build the final pathway, we should mention BMP4,
VDR, and PTHLH. Bone Morphogenetic Protein 4 (BMP4) is a member of the TGF- $\beta$ superfamily and is known to be important for the normal development of many tissues and organs, including the inner ear. Recent studies have demonstrated that Bmp4 heterozygous null $(B m p 4+/-)$ mice are viable and some adults exhibit an inner ear defect. ${ }^{37}$ Regarding VDR (Vitamin $D$ receptor), it seems to be important for a wide range of reasons and it has several important biological roles. VIT $D$ deficiency, $V D R$ malfunction, hypoparathyroidism, and hypervitaminosis have been suggested to be potential causes of sensorineural hearing loss. ${ }^{38}$ As a matter of fact, the VDR knockout mouse shows a severe calcification in the thalamus, causing an alteration of the connection between the inferior colliculus and auditory cortex. As mentioned before, an alteration of expression of parathyroid hormone is related to hearing and, to be more precise, this alteration could contribute to the abnormal bone turnover in otosclerosis; in this light PTHLH is another strong candidate. ${ }^{39}$

Of course, all the proteins present in the pathway can be taken into account as a basis for further in vitro functional experiments.

In conclusion, we report the first series of data on hearing quantitative traits (ie, normal hearing function). Candidate genes located in positive GWAS regions belong to several different gene families that show only a small overlap with those already identified as causing hearing impairments. However, present findings should be further confirmed and/or replicated in other populations/cohorts. Anyway, these results increase our knowledge of the molecular basis of normal hearing function and might open new perspectives for preventive and therapeutic strategies for hearing impairments.

Acknowledgements We thank Laura Esposito and Angela D'Eustacchio for technical support. We would like to acknowledge the invaluable contributions of the recruitment team from Korcula, the Croatian Centre for Global Health, University of Split, the administrative teams in Croatia and Edinburgh, and the people of Korcula and Split. We thank the Ogliastra population and all the individuals who participated in this study. We are very grateful to the municipal administrators for their collaboration on the project and for economic and logistic support.

Funding The study was partially funded by Telethon Foundation (GGP09037), Fondo Trieste (2008), Regione FVG (L.26.2008), and Italian Ministry of Health (RC16/06) (to PG). The KORCULA-CROATIA study in the Croatian island of Vis was supported through the grants from the Medical Research Council UK to HC, AFW and IR; and Ministry of Science, Education and Sport of the Republic of Croatia to IR. (number 108-1080315-0302). The SPLIT-CROATIA study was supported through the grants from the Medical Research Council UK; and Ministry of Science, Education and Sport of the Republic of Croatia. (number 108-1080315-0302). The Cilento study was supported by grants from the Italian Ministry of Universities (FIRB -RBIN064YAT) and the Ente Parco Nazionale del Cilento e Vallo di Diano to MC. RS was supported by a fellowship of Regione Campania, Italy.

Competing interests None.

Patient consent Obtained

Ethics approval Each population study participating to the consortium has been approved by the local ethical committee.

Provenance and peer review Not commissioned; externally peer reviewed.

\section{REFERENCES}

1. Steel KP, Kros CJ. A genetic approach to understanding auditory function. Nat Genet 2001;27:143-9.

2. Quint E, Steel KP. Use of mouse genetics for studying inner ear development. Curr Top Dev Biol 2003;57:45-83.

3. Van Laer L, Cryns K, Smith RJ, Van Camp G. Nonsyndromic hearing loss. Ear Hear 2003:24:275-88.

4. Martínez AD, Acuña R, Figueroa V, Maripillan J, Nicholson B. Gap-junction channels dysfunction in deafness and hearing loss. Antioxid Redox Signal 2009;11:309-22.

5. Hilgert N, Smith RJ, Van Camp G. Function and expression pattern of nonsyndromic deafness genes. Curr Mol Med 2010;9:546-64. 
6. Reiss M, Reiss G. Presbyacusis: pathogenesis and treatment. Med Monatsschr Pharm 2009:32:221-5

7. Konings A, Van Laer L, Van Camp G. Genetic studies on noise-induced hearing loss: a review. Ear Hear 2009;30:151-9.

8. Varilo T, Peltonen L. Isolates and their potential use in complex gene mapping efforts. Curr Opin Genet Dev 2004:14:316-23.

9. Shifman S, Darvasi A. The value of isolated populations. Nat Genet 2001;28:309-10.

10. Lowe JK, Maller JB, Pe'er I, Neale BM, Salit J, Kenny EE, Shea JL, Burkhardt R, Smith JG, Ji W. Genome-wide association studies in an isolated founder population from the Pacific Island of Kosrae. PLoS Genet 2009;5:e1000365.

11. Bedin E, Franzè A, Zadro C, Persico MG, Ciullo M, Hladnik U, Dolcetta D, Grasso DL, Riccardi P, Nutile T, Andrighetto G, D'Adamo P, Gasparini P, Marciano E. Age-related hearing loss in four Italian genetic isolates: an epidemiological study. Int $\mathrm{J}$ Audiol 2009;48:465-72.

12. Nelis M, Esko T, Mägi R, Zimprich F, Zimprich A, Toncheva D, Karachanak S, Piskácková T, Balascák I, Peltonen L, Jakkula E, Rehnström K, Lathrop M, Heath $S$, Galan P, Schreiber S, Meitinger T, Pfeufer A, Wichmann HE, Melegh B, Polgár N, Toniolo D, Gasparini P, D’Adamo P, Klovins J, Nikitina-Zake L, Kucinskas V, Kasnauskiene J, Lubinski J, Debniak T, Limborska S, Khrunin A, Estivill X, Rabionet R, Marsal S, Julià A, Antonarakis SE, Deutsch S, Borel C, Attar H, Gagnebin M. Macek M, Krawczak M, Remm M, Metspalu A. Genetic structure of Europeans: a view from the North-East. PLoS One 2009; 4:e5472.

13. Polasek O, Marusić A, Rotim K, Hayward C, Vitart V, Huffman J, Campbell S, Janković S, Boban M, Biloglav Z, Kolcić I, Krzelj V, Terzić J, Matec L, Tometić G, Nonković D, Nincević J, Pehlić M, Zedelj J, Velagić V, Juricić D, Kirac I, Belak Kovacević S, Wright AF, Campbell H, Rudan I. Genome-wide association study of anthropometric traits in Korčula Island, Croatia. Croat Med J 2009;50:7-16.

14. Fraumene C, Belle EM, Castrì L, Sanna S, Mancosu G, Cosso M, Marras F, Barbujani G, Pirastu M, Angius A. High resolution analysis and phylogenetic network construction using complete mtDNA sequences in sardinian genetic isolates. Mol Biol Evol 2006:23:2101-11.

15. Van Laer L, Huyghe JR, Hannula S, Van Eyken E, Stephan DA, Mäki-Torkko E, Aikio P, Fransen E, Lysholm-Bernacchi A, Sorri M, Huentelman MJ, Van Camp G. A genomewide association study for age-related hearing impairment in the Saami. Eur J Hum Genet 2010;18:685-93.

16. Aulchenko YS, Ripke S, Isaacs A, van Duijn CM. GenABEL: an R library for genomewide association analysis. Bioinformatics 2007;23:1294-6.

17. Aulchenko YS, Struchalin MV, van Duijn CM. ProbABEL package for genome-wide association analysis of imputed data. BMC Bioinformatics 2010:11:134.

18. Sajan SA, Warchol ME, Lovett M. Toward a systems biology of mouse inner ear organogenesis: gene expression pathways, patterns and network analysis. Genetics 2007; 177:631-53

19. Mansour SL, Twigg SR, Freeland RM, Wall SA, Li C, Wilkie AO. Hearing loss in a mouse model of Muenke syndrome. Hum Mol Genet 2009;18:43-50.

20. El-Amraoui A, Petit C. Cadherins as targets for genetic diseases. Cold Spring Harb Perspect Biol 2010;2:a003095.

21. Gabashvili IS, Sokolowski BH, Morton CC, Giersch AB. Ion channel gene expression in the inner ear. J Assoc res Otolaryngo 2007;8:305-28.

22. Wallner M, Meera P, Toro L. Molecular basis of fast inactivation in voltage and Ca2 +-activated K+ channels: a transmembrane beta-subunit homolog. Proc Natl Acad Sci U S A 1999;96:4137-42.

23. Sahlender DA, Roberts RC, Arden SD, Spudich G, Taylor MJ, Luzio JP, KendrickJones J, Buss F. Optineurin links myosin VI to the Golgi complex and is involved in Golgi organization and exocytosis. J Cell Biol 2005;169:285-95.

24. Hu BH, Cai Q, Manohar S, Jiang H, Ding D, Coling DE, Zheng G, Salvi R. Differential expression of apoptosis-related genes in the cochlea of noise-exposed rats. Neuroscience 2009;161:915-25.

25. Carninci P, Kasukawa T, Katayama S, Gough J, Frith MC, Maeda N, Oyama R, Ravasi T, Lenhard B, Wells C, Kodzius R, Shimokawa K, Bajic VB, Brenner SE, Batalov S, Forrest AR, Zavolan M, Davis MJ, Wilming LG, Aidinis V, Allen JE, AmbesiImpiombato A, Apweiler R, Aturaliya RN, Bailey TL, Bansal M, Baxter L, Beisel KW, Bersano T, Bono H, Chalk AM, Chiu KP, Choudhary V, Christoffels A, Clutterbuck DR, Crowe ML, Dalla E, Dalrymple BP, de Bono B, Della Gatta G, di Bernardo D, Down T, Engstrom P, Fagiolini M, Faulkner G, Fletcher CF, Fukushima T, Furuno M, Futaki S, Gariboldi M, Georgii-Hemming P, Gingeras TR, Gojobori T, Green RE, Gustincich S,
Harbers M, Hayashi Y, Hensch TK, Hirokawa N, Hill D, Huminiecki L, lacono M, Ikeo K Iwama A, Ishikawa T, Jakt M, Kanapin A, Katoh M, Kawasawa Y, Kelso J, Kitamura H, Kitano H, Kollias G, Krishnan SP, Kruger A, Kummerfeld SK, Kurochkin IV, Lareau LF, Lazarevic D, Lipovich L, Liu J, Liuni S, McWilliam S, Madan Babu M, Madera M, Marchionni L, Matsuda H, Matsuzawa S, Miki H, Mignone F, Miyake S, Morris K, Mottagui-Tabar S, Mulder N, Nakano N, Nakauchi H, Ng P, Nilsson R, Nishiguchi S, Nishikawa S, Nori F, Ohara O, Okazaki Y, Orlando V, Pang KC, Pavan WJ, Pavesi G, Pesole G, Petrovsky N, Piazza S, Reed J, Reid JF, Ring BZ, Ringwald M, Rost B, Ruan Y, Salzberg SL, Sandelin A, Schneider C, Schönbach C, Sekiguchi K, Semple CA, Seno S, Sessa L, Sheng Y, Shibata Y, Shimada H, Shimada K, Silva D, Sinclair B, Sperling S, Stupka E, Sugiura K, Sultana R, Takenaka Y, Taki K, Tammoja K, Tan SL, Tang S, Taylor MS, Tegner J, Teichmann SA, Ueda HR, van Nimwegen E, Verardo R, Wei CL, Yagi K, Yamanishi H, Zabarovsky E, Zhu S, Zimmer A, Hide W, Bult C, Grimmond SM, Teasdale RD, Liu ET, Brusic V, Quackenbush J, Wahlestedt C, Mattick JS, Hume DA Kai C, Sasaki D, Tomaru Y, Fukuda S, Kanamori-Katayama M, Suzuki M, Aoki J, Arakawa T, lida J, Imamura K, Itoh M, Kato T, Kawaji H, Kawagashira N, Kawashima T, Kojima M, Kondo S, Konno H, Nakano K, Ninomiya N, Nishio T, Okada M, Plessy C, Shibata K, Shiraki T, Suzuki S, Tagami M, Waki K, Watahiki A, Okamura-Oho Y, Suzuki H, Kawai J, Hayashizaki Y; FANTOM Consortium; RIKEN Genome Exploration Research Group and Genome Science Group (Genome Network Project Core Group). The transcriptional landscape of the mammalian genome. Science 2005;309:1559-63.

26. Scherer SW, Soder S, Duvoisin RM, Huizenga JJ, Tsui LC. GRM8 The human metabotropic glutamate receptor 8 (GRM8) gene: a disproportionately large gene located at 7q31.3-q32.1. Genomics 1997;44:232-6.

27. Krejci P, Prochazkova J, Bryja V, Kozubik A, Wilcox WR. Molecular pathology of the fibroblast growth factor family. Hum Mutat 2009:30:1245-55.

28. D'Souza M, Zhu X, Frisina RD. Novel approach to select genes from RMA normalized microarray data using functional hearing tests in aging mice. J Neurosci Methods 2008;171:279-87.

29. Cellanetti M, Gunda V, Wang L, Macchiarulo A, Pellicciari R. Insights into the binding mode and mechanism of action of some atypical retinoids as ligands of the small heterodimer partner (SHP) LPPR5. J Comput Aided Mol Des 2010;24:943-56.

30. Bryant J, Goodyear RJ, Richardson GP. Sensory organ development in the inner ear: molecular and cellular mechanisms. Br Med Bull 2002;63:39-57.

31. Goodyear RJ, Legan PK, Wright MB, Marcotti W, Oganesian A, Coats SA, Booth CJ, Kros CJ, Seifert RA, Bowen-Pope DF, Richardson GP. A receptor-like inositol lipid phosphatase is required for the maturation of developing cochlear hair bundles. J Neurosci 2003;23:9208-19.

32. Drew LJ, Rugiero F, Cesare P, Gale JE, Abrahamsen B, Bowden S, Heinzmann S, Robinson M, Brust A, Colless B, Lewis RJ, Wood JN. High-threshold mechanosensitive ion channels blocked by a novel conopeptide mediate pressureevoked pain. Plos One 2007:2:e515.

33. Milo M, Cacciabue-Rivolta D, Kneebone A, Van Doorninck H, Johnson C, LawokoKerali G. Niranjan M, Rivolta M. Holley M. Genomic analysis of the function of the transcription factor gata3 during development of the mammalian inner ear. PLoS One 2009; 4:e7144.

34. Friedman RA, Van Laer L, Huentelman MJ, Sheth SS, Van Eyken E, Corneveaux JJ, Tembe WD, Halperin RF, Thorburn A0, Thys S, Bonneux S, Fransen E, Huyghe J, Pyykkö I, Cremers CW, Kremer H, Dhooge I, Stephens D, Orzan E, Pfister M, Bille M, Parving A, Sorri M, Van de Heyning PH, Makmura L, Ohmen JD, Linthicum FH Jr, Fayad JN, Pearson JV, Craig DW, Stephan DA, Van Camp G. GRM7 variants confe susceptibility to age-related hearing impairment. Hum Mol Genet 2009;18:785-96.

35. Vrijens K, Van Camp G, Van Laer L. Characterization of the murine Dfna5 promoter and regulatory regions. Gene 2009;432:82-90.

36. Canlon B, Meltser I, Johansson P, Tahera Y. Glucocorticoid receptors modulate auditory sensitivity to acoustic trauma. Hear Res 2007:226:61-9.

37. Blauwkamp MN, Beyer LA, Kabara L, Takemura K, Buck T, King WM, Dolan DF, Barald KF, Raphael Y, Koenig RJ. The role of bone morphogenetic protein 4 in inner ear development and function. Hear Res 2007;225:71-9.

38. Zou J, Minasyan A, Keisala T, Zhang Y, Wang JH, Lou YR, Kalueff A, Pyykkö I, Tuohimaa P. Progressive hearing loss in mice with a mutated vitamin D receptor gene. Audiol Neurootol 2008;13:219-30.

39. Grayeli AB, Sterkers O, Roulleau P, Elbaz P, Ferrary E, Silve C. Parathyroid hormoneparathyroid hormone-related peptide receptor expression and function in otosclerosis Am J Physiol 1999;277:E1005-12. 